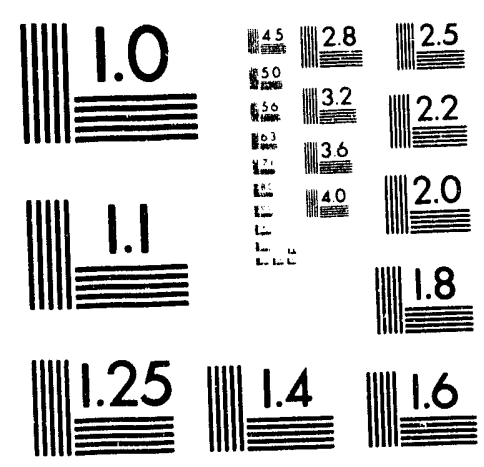



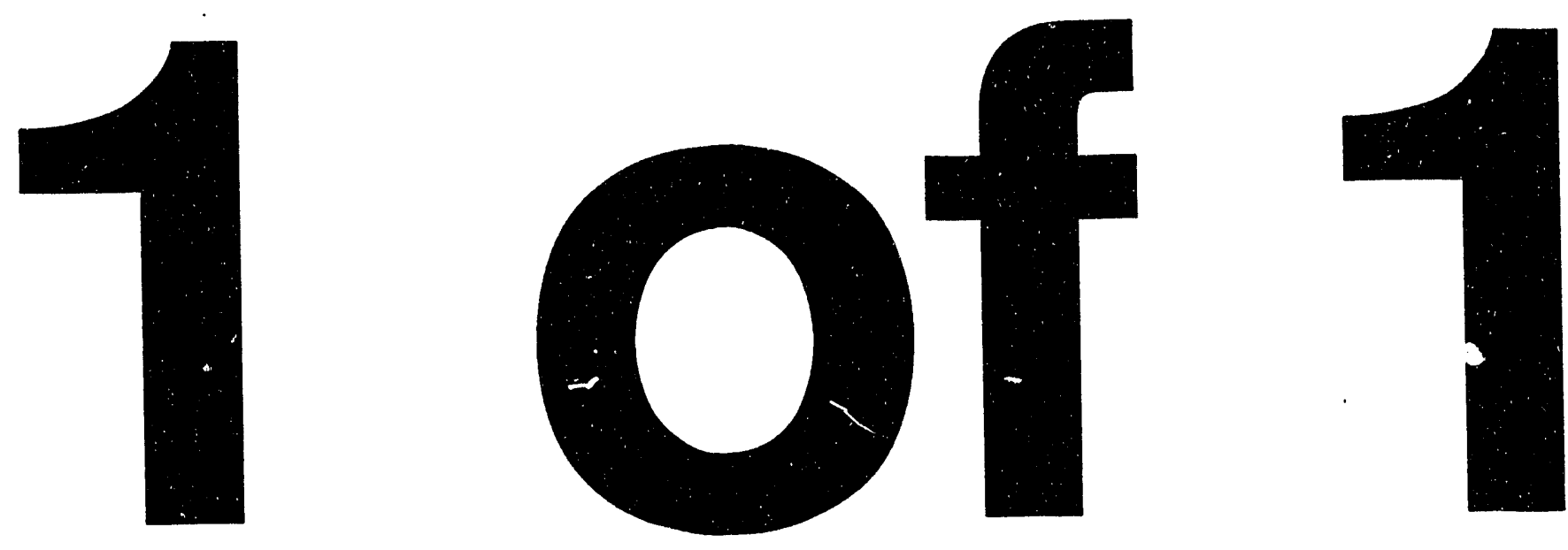


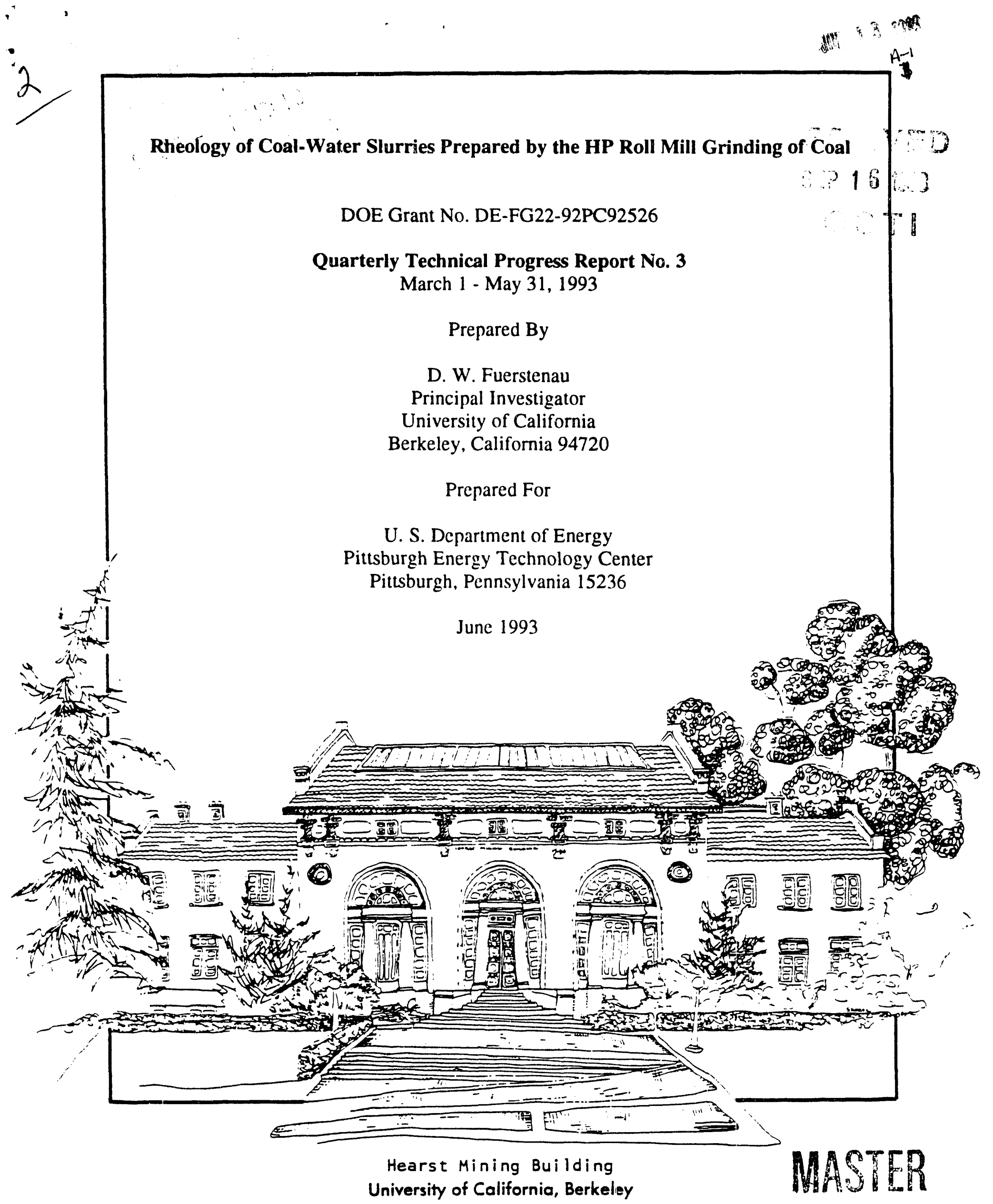

DISTRIBUTION OF THIS DOCUMENT IS UIVLIMITED gfD 


\title{
Rheology of Coal-Water Slurries Prepared by the HP Roll Mill Grinding of Coal
}

\author{
DOE Grant No. DE-FG22-92PC92526 \\ Quarterly Technical Progress Report No. 3 \\ March 1 - May 31, 1993
}

\section{INTRODUCTION}

The objective of this research is the development of improved technology for the preparation of coal-water slurries, that have potential for replacing fuel oil in direct combustion. This should be of major importance to the United States in its efforts to reduce dependence on imported oil and to rely more fully on its enormous low-cost coal resources.

In Quarterly Report No. 1, we summarized preliminary results on the rhcological behavior of coal-water slurries prepared from Pittsburgh No. 8 cual that had been ground in a ball mill under various conditions. Quarterly Report No. 2 presented the results of studies of the effect of solids content and the immobilization of water on the rheological behavior of coalwater slurries. We also reported the reproducibility of the rheological measurements using a Haake viscometer with a MV-II sensor and the procedures for calculating the viscosity using the Heschel-Buckley equation. Comparison of the rheological behavior of coal-water slurries measured with the Haaki viscometer and a Brookfield viscometer was also discussed in Quarterly Report No. 2.

During the third quarter, our research efforts were directed towards the selection of the best sensor system for the Haake RV-12 viscometer for measuring the rheological behavior of coal-water slurries at high solids content and the effect of the Triton $\mathrm{X}$ series of nonionic surfactants on the theological behavior of coal-water slurries. Details of these investigations are presented in the following paragraphs.

\section{DISCLAIMER}

This report was prepared as an account of work sponsored by an agency of the United States Government. Neither the United States Government nor any agency thereof, nor any of their employees, makes any warranty, express or implied, or assumes any legal liability or responsibility for the accuracy, completeness, or usefulness of any information, apparatus, product, or process disclosed, or represents that its use would not infringe privately owned rights. Reference herein to any specific commercial product, process, or service by trade name, trademark, manufacturer, or otherwise does not necessarily constitute or imply its endorsement, recommendation, or favoring by the United States Government or any agency thereof. The views and opinions of authors expressed herein do not necessarily state or reflect those of the United States Government or any agency thereof. 


\section{COMPARISON OF MV-II WITH MV-DIN SENSOR SYSTEMS FOR THE HAA KE VISCOMETER}

In Quarterly Report No. 2, we compared the rheological behavior of coal-water slurries measured using the Haake RV-12 viscometer with a MV-II sensor and the Brookfield LVT viscometer with a No 4 spindle and found that the Haake viscometer is superior to the Brookfield viscometer for coal-water slurries because it can determine the shear stress, the apparent viscosity and the absolute viscosity over a wider range of shear rates under more precise temperature-controlled environments. However, for coal-water slurries with high solids contents, the slurry may attach to the bottom face of the rotor (endface effect) and phase separation may also occur during viscosity measurements using the Hake viscometer with a MV-II sensor. In order to find a better sensor system for the Haake viscometer, experiments were carried out in this quarter to compare the rheological behavior of coal-water slurries obtained with a MV-DIN sensor system with that obtained with the MV-II sensor. The physical parameters for these sensor systems are given in Table 1.

In this part of our study, the Haake RV-12 viscometer with each sensor system was first calibrated using a Newtonian fluid (glycerol $99.5+\%$ purity) with a viscosity of $1474 \mathrm{mPa} . \mathrm{s}$ at $20{ }^{\circ} \mathrm{C}$. For each sensor system, three samples of coal-water slurries with $60 \%$ solids content were prepared with Pittsburgh No. 8 coal that had been dry ground to 90 percent minus 200 mesh. No additives were used in preparing the slurries. After conditioning at $20^{\circ} \mathrm{C}$ in a shaker for 16 hours, the shear stress of each slurry was measiricd as a function of shear rate using the Haake RV-12 viscometer with each sensor system. The reported values are the average results of three measurements for each of the three samples. The viscosity of a slurry at different shear

Table 1 - Physical parameters of the sensor systems for the Haake viscometer tested in this study.

\begin{tabular}{|c|c|c|c|c|}
\hline Sensor system & Rotor radius, $\mathrm{R}_{\mathrm{i}}, \mathrm{mm}$ & Cup radius, $R_{\mathbf{a}}, \mathrm{mm}$ & $\mathrm{R}_{\mathrm{a}} / \mathrm{R}_{\mathrm{i}}$ & Gap, mm \\
\hline MV-II & 18.40 & 21.00 & 1.14 & 2.60 \\
\hline MV-DIN & 19.36 & 21.00 & 1.08 & 1.64 \\
\hline
\end{tabular}


rates was calculated by fitting the experimental results to the Heschel-Buckley equation, using the same procedures as described in Quarterly Report No. 2.

Figures 1 and 2 present the shear stress and the viscosity of the slurry as a function of shear rate for the two sensor systems. The results obtained with both the MV-II and MV-DIN sensor systems show that a coal-water slurry containing $60 \mathrm{wt} \%$ solids content behaves as a pseudoplastic fluid with a yield stress, that is, the viscosity of the slurry is shear-dependent, which decreases as the shear rate increases. However, at the same shear rate, both the shear stress and the viscosity of the slurry measured using MV-DIN sensor system are higher than that measured using MV-II sensor system. This may be due to the conical shape in the bottom of the MV-DIN sensor system that permits the rotor to penetrate the suspension without inducing phase separation (thinning of the suspension in the gap between the rotor and the cup). This decreases the measured values of the shear stress and the viscosity. Furthermore, at a given shear rate, higher value of the signal S reading (which relates to the torque) was obtained with the MV-DIN sensor than that with the MV-II sensor, which increases the accuracy of the measurements since the noise level ( $\pm 1 \mathrm{~S}$ scale unit) is constant. The standard deviation of the torque in the three measurements is $6.0 \%$ for the MV-DIN sensor system compared with $9.3 \%$ for the MV-II sensor system. These results clearly show that the MV-DIN sensor system is better than the MV-II sensor system for measuring the rheological behavior of coal-water slurries with high solids content.

However, there are also limitations for measuring the rheological behavior of concentrated coal-water slurries using the Haake RV-12 viscometer with the MV-DIN sensor system. As an example. Figure 3 plots the shear stress as a function of shear rate for coal-water slurries with $60 \mathrm{wt} \%$ solids content at various surfactant additions. Figure 4 gives the shear stress as a function of shear rate for coal-water slurries with different solids contents at $1 \%$ surfactant addition. It can be seen from the results presented in these two figures that the 


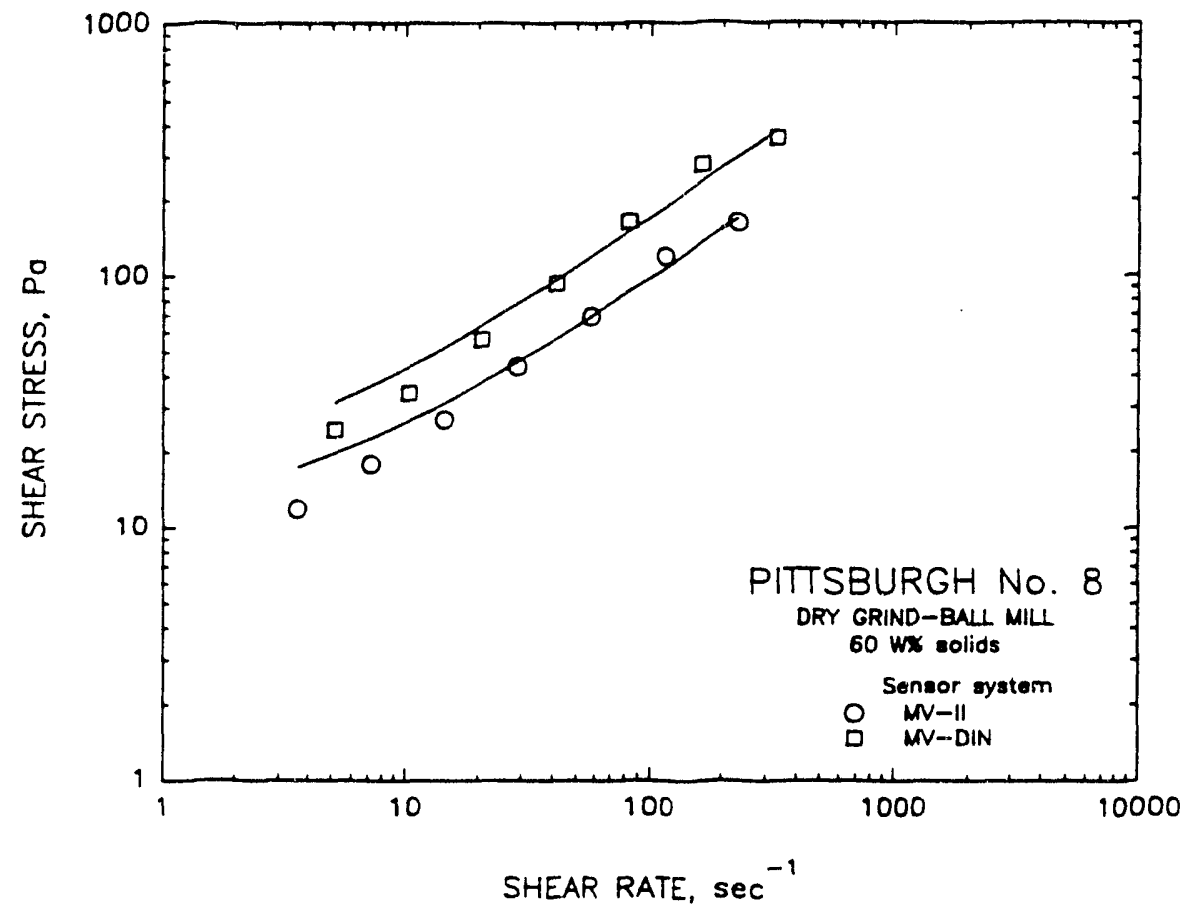

Figure 1. Shear stress as a function of shear rate for Pittsburgh No. 8 coal-water slurries corauining 60 wt\% solids content measured with the MV-II and MV-DIN sensor systems at $20^{\circ} \mathrm{C}$.

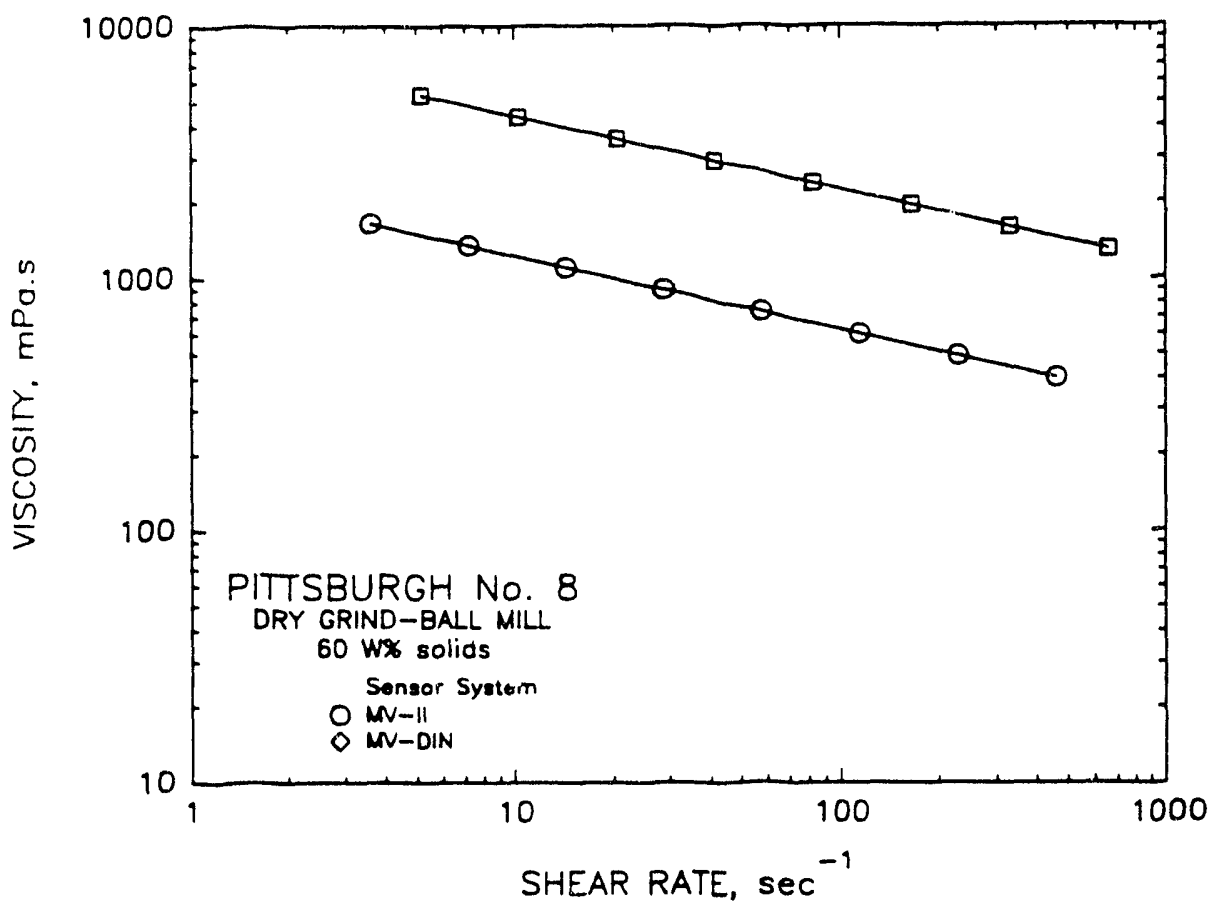

Figure 2. Viscosity curve for Pittsburgh No. 8 coal-wate- slurries containing $60 \mathrm{wt} \%$ solids content measured with the MV-II and MV-DIN sensor systems at $20^{\circ} \mathrm{C}$. 


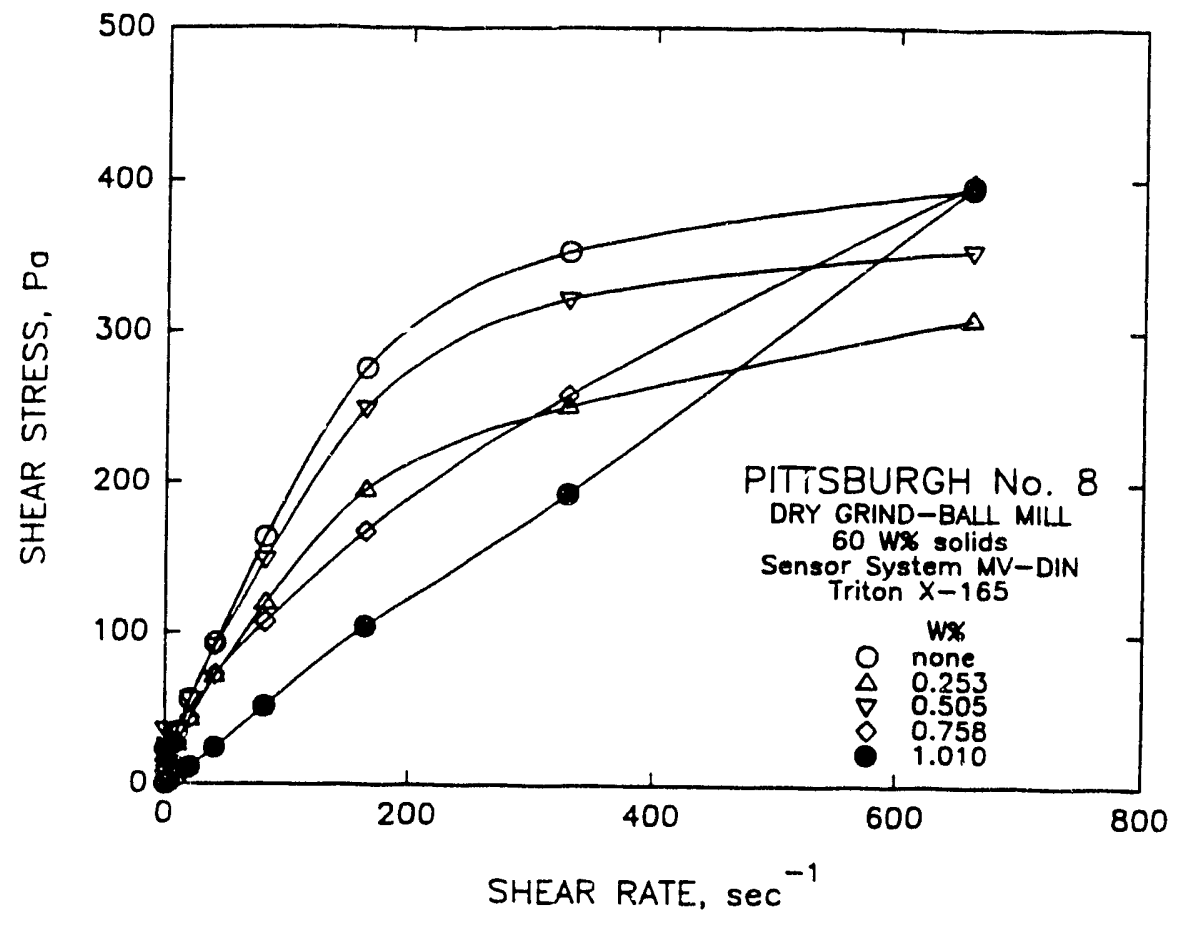

Figure 3. Flow curves (rheograms) for Pittsburgh No. 8 coal-water slurries containing $60 \mathrm{wt} \%$ solids content in presence of various Triton X-165 additions.

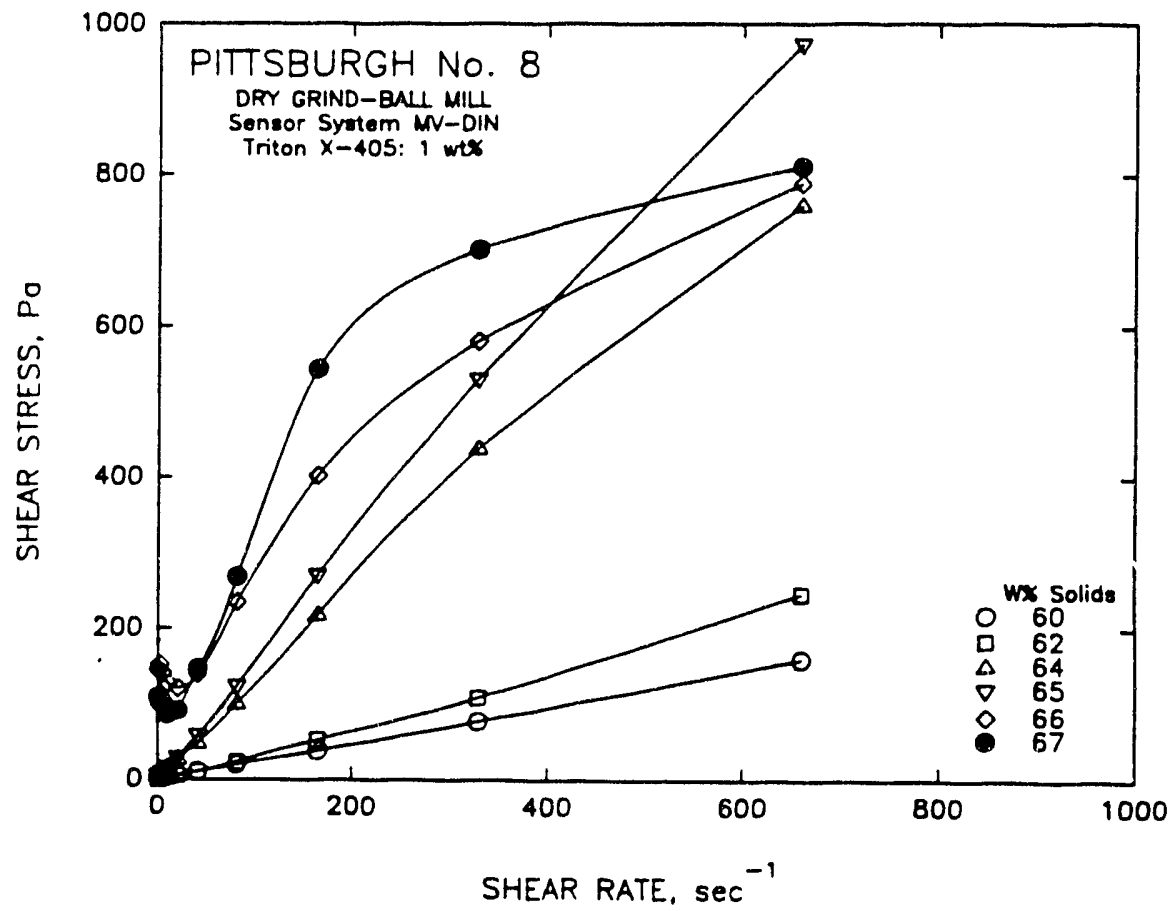

Figure 4. Flow curves (rheograms) for Pittsburgh No. 8 coal-water slurries with different solids contents in the presence of $1 \mathrm{wt} \%$ Triton $\mathrm{X}-405$. 
rate of increase in the shear stress decreases significantly when the shear rate increases over 200 $\sec ^{-1}$ for these slurries having a higher viscosity (curves for $0,0.253$ and $0.505 \mathrm{wt} \%$ surfactant additions in Figure 3 and curves for 66 and 67 wt\% coal in Figure 4). It appears that the change in slope that occurs at the same shear rate for different slurries is due to the slip of the slurries over the surface of the rotor at high shear rate. Therefore, the results obtained at shear rates higher than $200 \mathrm{sec}^{-1}$ may not be very reliable. As a consequence, these data will not be used in calculating the viscosity of the slurries using the Heschel-Buckley equation. Similarly, the results obtained in very low shear rate (the signal $\mathbf{S}$ reading is close to the noise level of the instrument) will also not be used in the calculation.

\section{EFFECT OF CHEMICAL ADDITIVES}

In the manufacture of coal-water slurry fuels, various chemical additives are used to impreve their rheological behavior. During this third quarter, study of the effect of chemical additives was initiated using the Triton $X$ series of nonionic surfactants $\left[\mathrm{C}_{8} \mathrm{H}_{17}-\mathrm{C}_{6} \mathrm{H}_{4}-\left(\mathrm{O}-\mathrm{CH}_{2}\right.\right.$ $\left.\mathrm{CH}_{2}\right)_{n}-(\mathrm{OH}$. The following five surfactants with different number of ethoxy groups were tested: Triton X-10) $(n=9-10)$, Triton X-102 ( $n=12-13)$, Triton X-165 (n=16), Triton X-305 ( $n=30)$, and Triton X-405 $(n=40)$. Slurries were prepared with Pittsburgh No. 8 coal that had been dry ground (1) 9() percent minus 200 mesh and then conditioned at $20^{\circ} \mathrm{C}$ in a shaker for 16 hours. Then the shear stress of each slurry was measured as a function of shear rate using the Haake RV-12 viscometer with the MV-DIN sensor system.

Figure 5 shows the flow curves for Pittsburgh No. 8 coal-water slurries at different additions of Triton $X-165$. It can be seen from the results given in Figure 5 that the shear stress of the slurrics generally decreases with increasing Triton X-165 additions at a fixed shear rate, except at 0.253 wt\% addition. Furthermore, the coal slurries behave as pseudoplastic fluids with a yield stress until the reagent addition is higher than $0.76 \mathrm{wt} \%$. At an addition of $1.01 \mathrm{wt} \%$ 
Triton X-165 the rheological behavior of the slurries trends to approach that of a Bingham type of fluid.

Figure 6 presents the viscosity of the slurry as a function of the Triton $\mathrm{X}-165$ addition at three different shear rates. The results given in this figure show that the viscosity of the slurries decreases at Triton X-165 addition of $0.25 \mathrm{wt} \%$ and then increases slightly at $0.50 \mathrm{wt} \%$ addition. The viscosity of the slurries decreases further at higher reagent additions $0.76 \mathrm{wt} \%$ and 1.01 $w t \%$. This behavior could be related to the balance between the decrease in the particle-particle attraction (decrease viscosity) and the increase in the effective volume radii of the particles (increase viscosity) as the adsorption of the hydrophilic ethylene oxides groups increases $(1,2)$. Furthermore, ilicreasing the shear rate decreases slightly the viscosity of the slurries until the reagent addition reaches $1.0 \mathrm{wt} \%$. At this high dosage, viscosity was found to be independent of shear rate.

In the case of Triton X-100, Triton X-102, Triton X-305, and Triton X-405, similar hehavior was observed. For example. Figure 7 presents the viscosity as a function of the addition of Triton X-100, Triton X-165, and Triton X-405 reagents. Clearly, an increase in reagent addition for the Triton $\mathrm{X}$ series follows the general behavior described for Triton X-165. The effect of the number of ethylene oxide groups in a surfactant molecule on the viscosity of a coal-water slurry is given in Figure 8. It can be seen from the results in this figure that at low reagent addition $(0.13 \mathrm{wt} \%$ and $0.5 \mathrm{wt} \%)$ the effect of the number of ethylene oxide groups is insignificant. However, at high reagent addition (1.0 wt\%), the viscosity of the slurries decreases significantly with the increase in the number of ethylene oxide groups in the surfactant molecule. This is due to the more hydrophilic nature of molecules having a larger number of ethylene oxide groups as compared to those with a small number of ethylene oxide groups. 


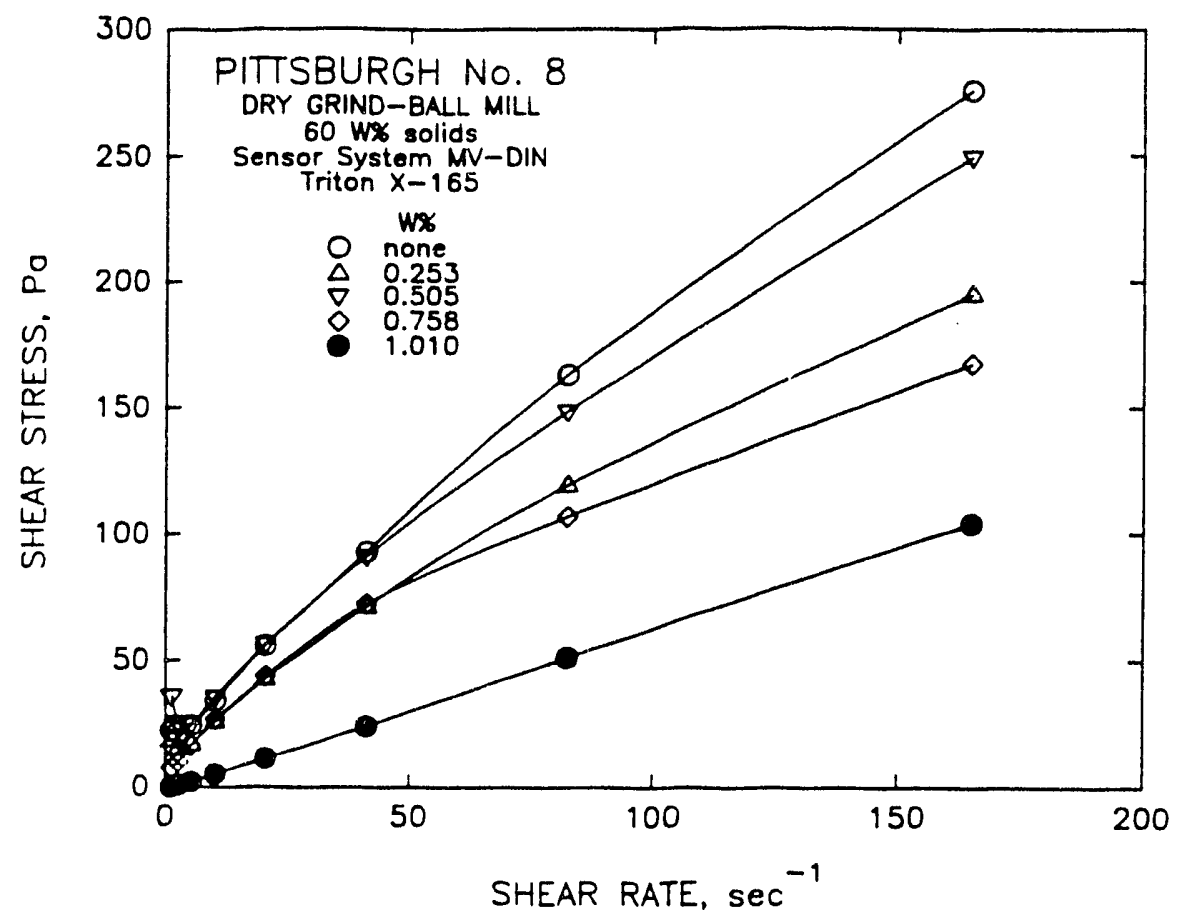

Figure 5. Shear stress as a function of shear rate for Pittsburgh No. 8 coal-water slurries containing $60 \mathrm{wt} \%$ solids content in presence of various Triton X-165 additions.

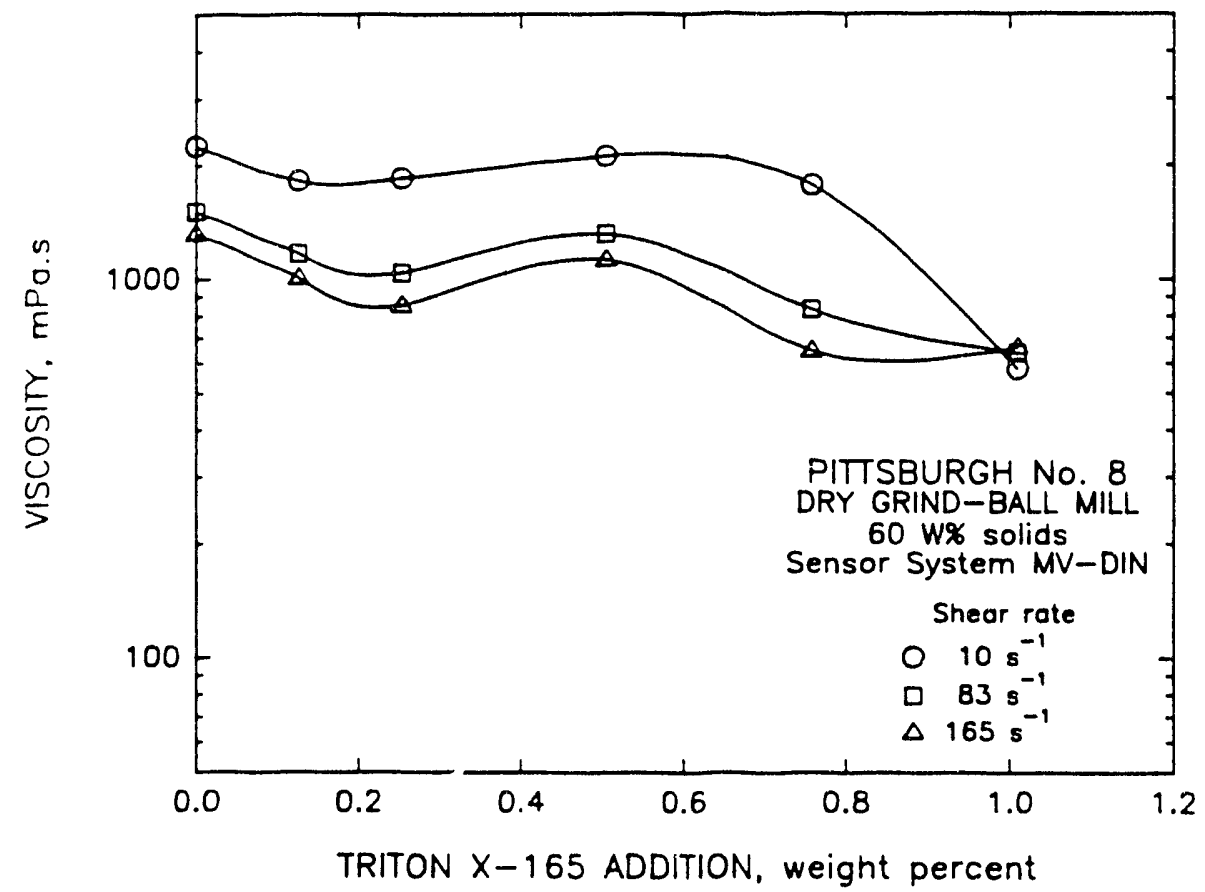

Figure 6. Effect of Triton X-165 addition on the viscosity of Pittsburgh No. 8 coal-water slurries containing $60 \mathrm{wt} \%$ solids content at three different shear rates. 


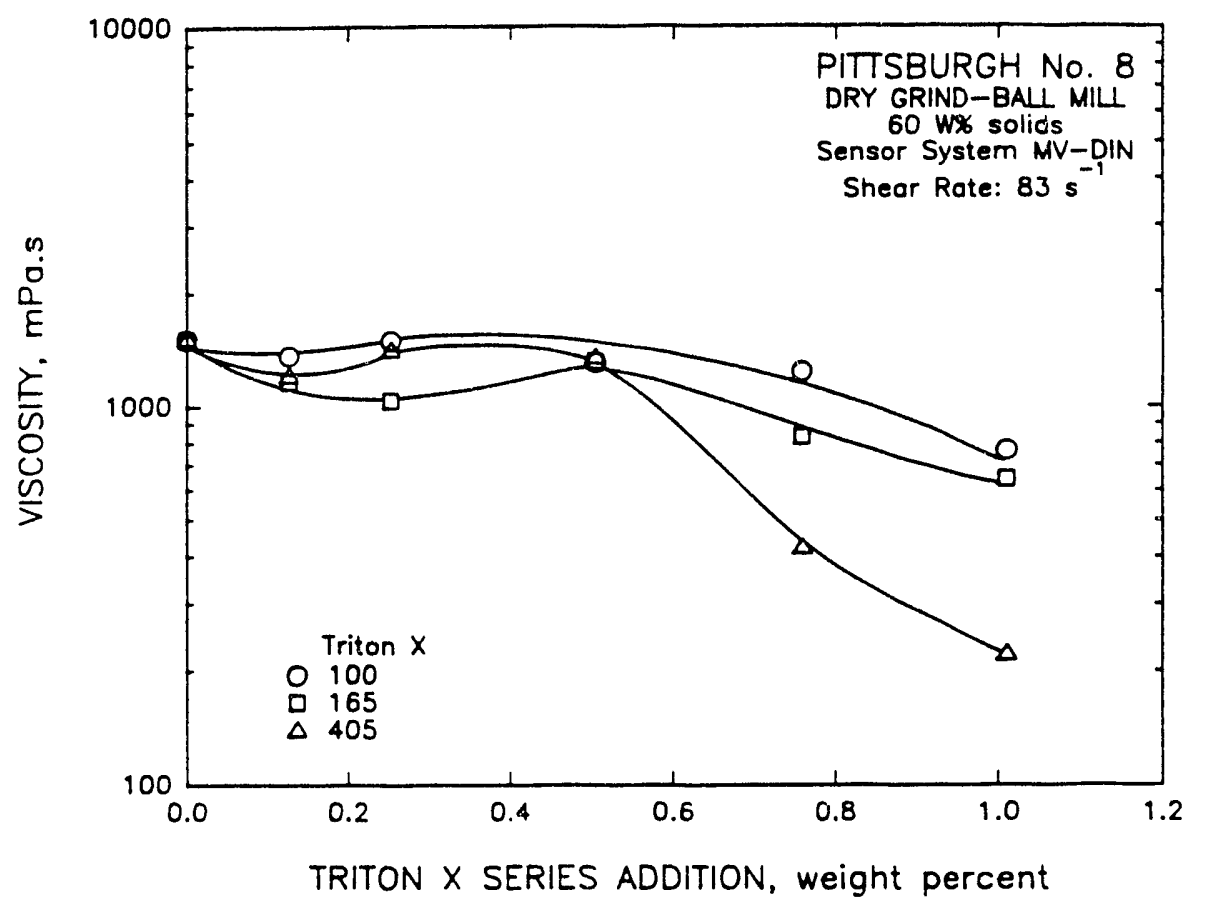

Figure 7. Effect of addition of different surfactants on the viscosity of Pittsburgh No. 8 coal-water slurries containing $60 \mathrm{wt} \%$ solids content at a shear rate of $83 \mathrm{~s}^{-1}$.

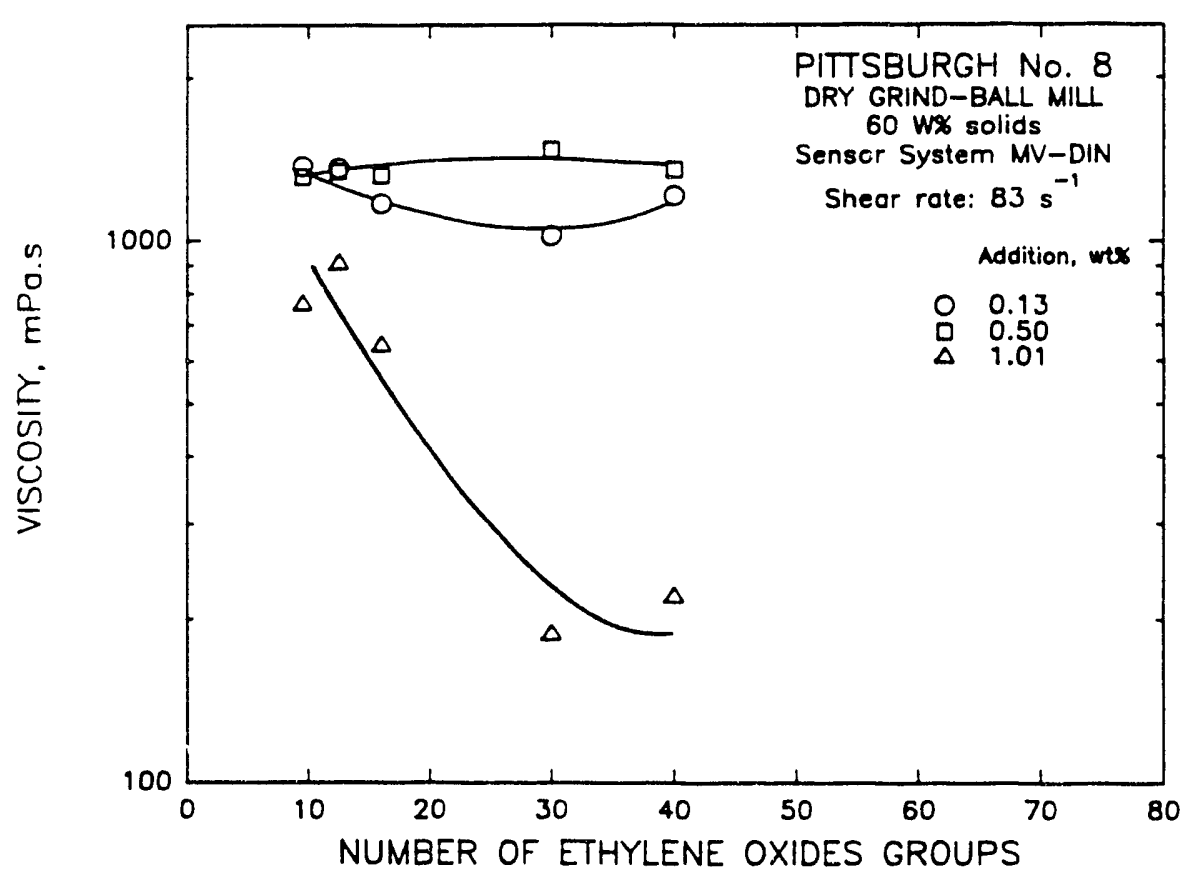

Figure 8. Viscosity of Pittsburgh No. $8 \mathrm{coal}$-water slurries as a function of the number of ethylene oxides groups in the surfactant molecule at a shear rate of $83 \mathrm{~s}^{-1}$. 


\section{EFFECT OF SOLIDS CONTENT ON THE RHEOLOGY OF COAL-WATER SLURRIES IN PRESENCE OF TRITON X-405}

To study the effect of solids content on the rheology of coal-water slurries in presence of chemical additives, Triton X-405 was used because at $1 \mathrm{wt} \%$ addition it significantly reduces the viscosity of the coal-water slurries. Figure 9 presents the shear stress as a function of shear rate for Pittsburgh No. 8 coal-water slurries at different solids contents in the presence of 1 wt\% Triton X-405. Clearly, as the solids content of the slurries increases, the shear stress increases at a given shear rate. At high solids contents (66\% and 67\%), a significant yield stress was observed. Figure 10 shows the effect of solids content on the viscosity of Pittsburgh No. 8 coalwater slurries in presence of 1 wt\% of Triton X-405. The viscosity of the slurries increases sharply as the solids content increases. This increase is mainly due to hydrodynamic effects, that is, the decrease in available water for the coal particles to flow at high soiids content. Over 67 wt\% solids, the material presents the texture of a dry paste and, therefore, rheological measurements cannot be cronducted. In contrast, without chemical additives, the upper limit of the solids content at which measurements can be made is only $63 \mathrm{wt} \%$.

\section{SUMMARY}

By comparing the rheological behavior of Pittsburgh No. 8 coal-water slurries obtained when using the Haake RV-12 viscometer with both the MV-Il and MV-DIN sensor systems, we found that the MV-DIN sensor system performs better than the MV-II sensor system for slurries with high solids content.

For studying the effect of chemical additives on the rheology of coal-water slurries, the Triton $X$ series of nonionic surfactants was used. The addition of these nonionic surfactants significantly reduces the viscosity of the slurries, especially at higher reagent additions ( $1 \mathrm{wt} \%$ ). Those Triton $\mathrm{X}$ nonionic surfactants having a larger number of ethoxy groups in the molecules are more effective for reducing the viscosity of a slurry than the surfactants with a smaller 


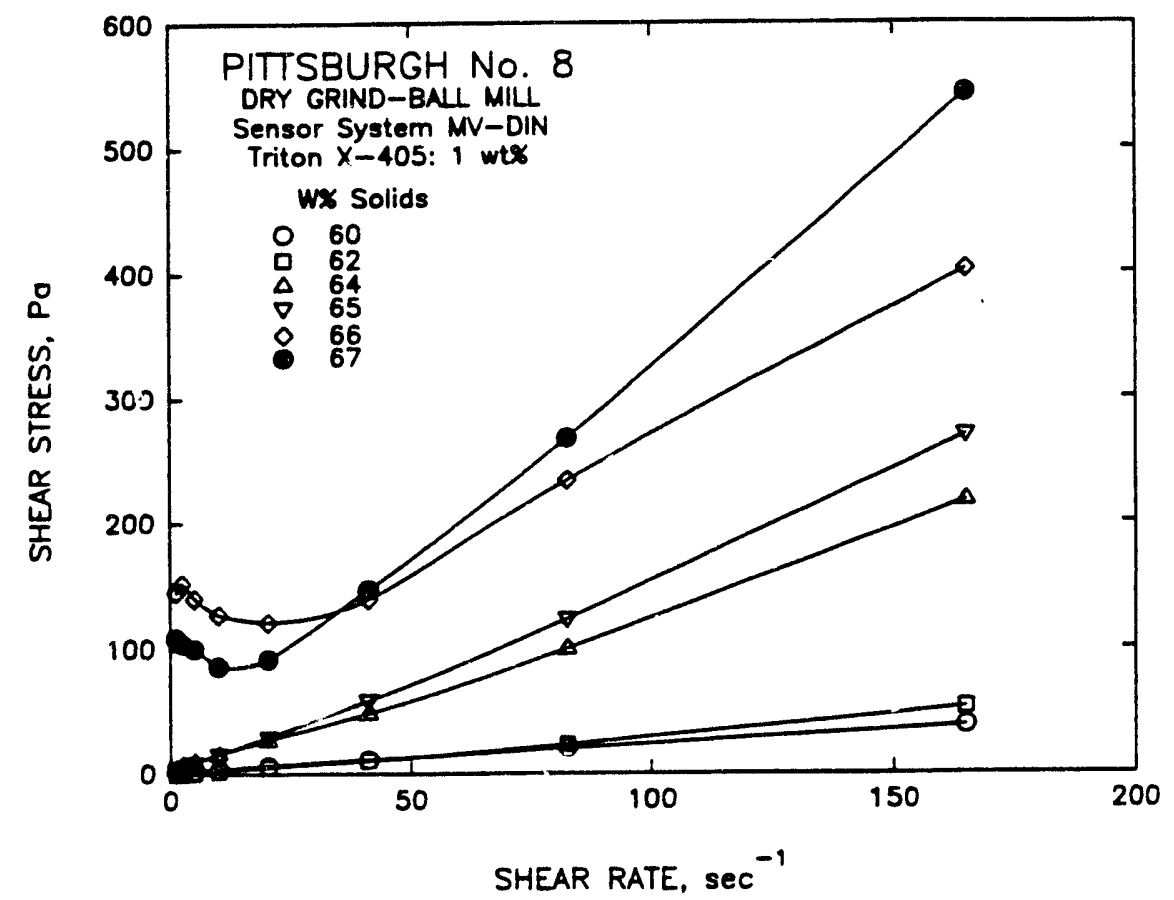

Figure 9. Shear stress as a function of shear rate for Pittsburgh No. 8 coal-water slurries with different solids contents in the presence of 1 wt\% Triton X-405.

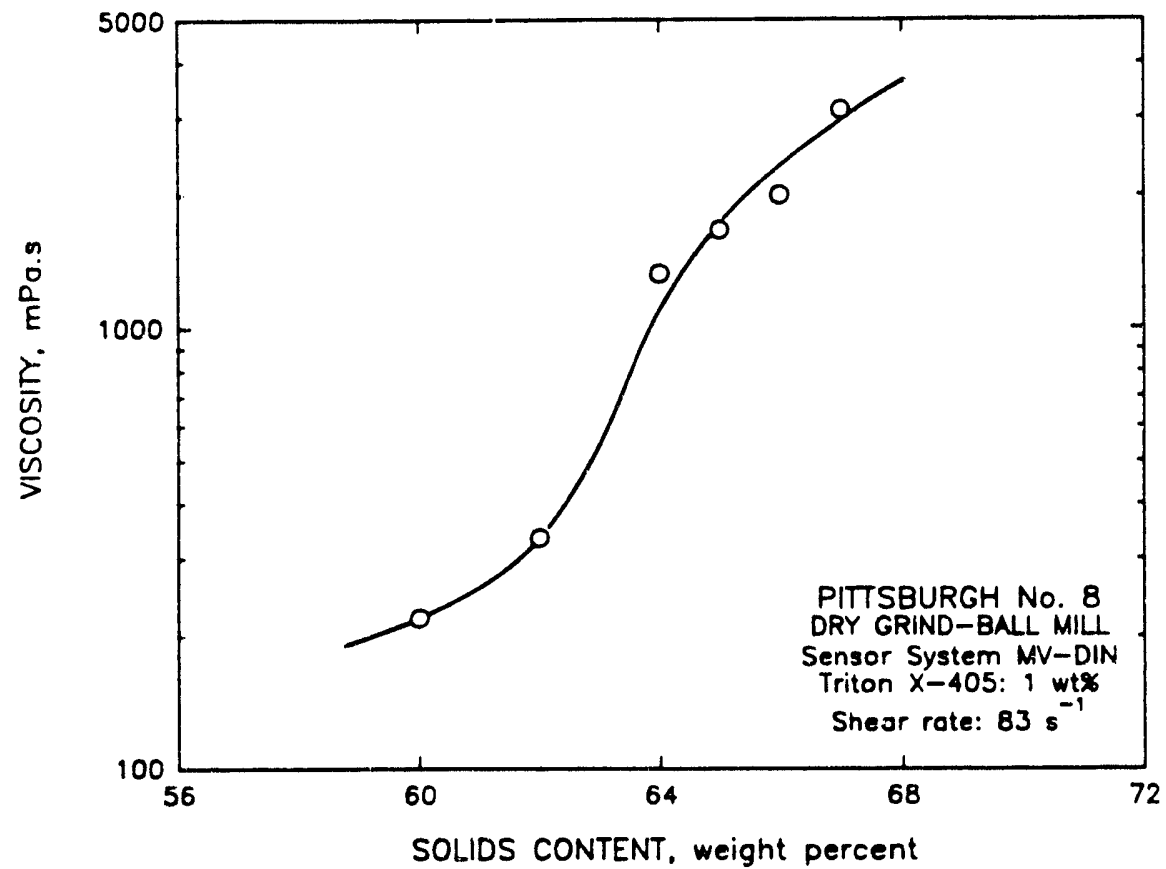

Figure 10. Viscosity of Pittsburgh No. 8 coal-water slurries as a function of solids content in the presence of $1 \mathrm{wt} \%$ Triton $X-405$ at a shear rate of $83 \mathrm{~s}^{-1}$. 
number of ethoxy groups because of the hydrophilic nature of ethoxy groups.

In studying the effect of the solids content in the presence of 1 wt\% Triton X-405 (dry coal basis), slurry viscosity was found to increase sharply with increasing solids content. Those slurries with high solids content ( $66 \mathrm{wt} \%$ and $67 \mathrm{wt} \%$ ) have a significant yield stress, even at an addition of 1 wt $\%$ of Triton X-405. The maximum solids content of slurries that could be used in the presence of $1 w t \%$ Triton $X-405$ is 67 percent.

\section{RESEARCH WORK PLAN FOR NEXT QUARTER}

During the fourth quarter, investigation of chemical additives on the viscosity, sedimentation rate, and sedimentation volume of coal-water slurries will be continued. The preparation of the fine coal by grinding it in the high-pressure roll mill will be initiated.

\section{REFERENCES}

1. M. Lindheimer, E. Keh, S. Zaini and S. Partyka, "Interfacial Aggregation of Nonionic Surfactants onto Silica Gel: Calorimetric Evidence," J. of Colloid and Interface Science, Vol. 138, pp. 83-91 (1991).

2. G. D. Botsaris and Y. M. Glazman, "Stability and Rheology of Coal Slurries," in Interfacial Phenomena in Coal Technology, G. D. Botsaris and Y. M. Glazman, eds., Marcel Dekker, Inc., New York, pp. 199-277 (1989). 

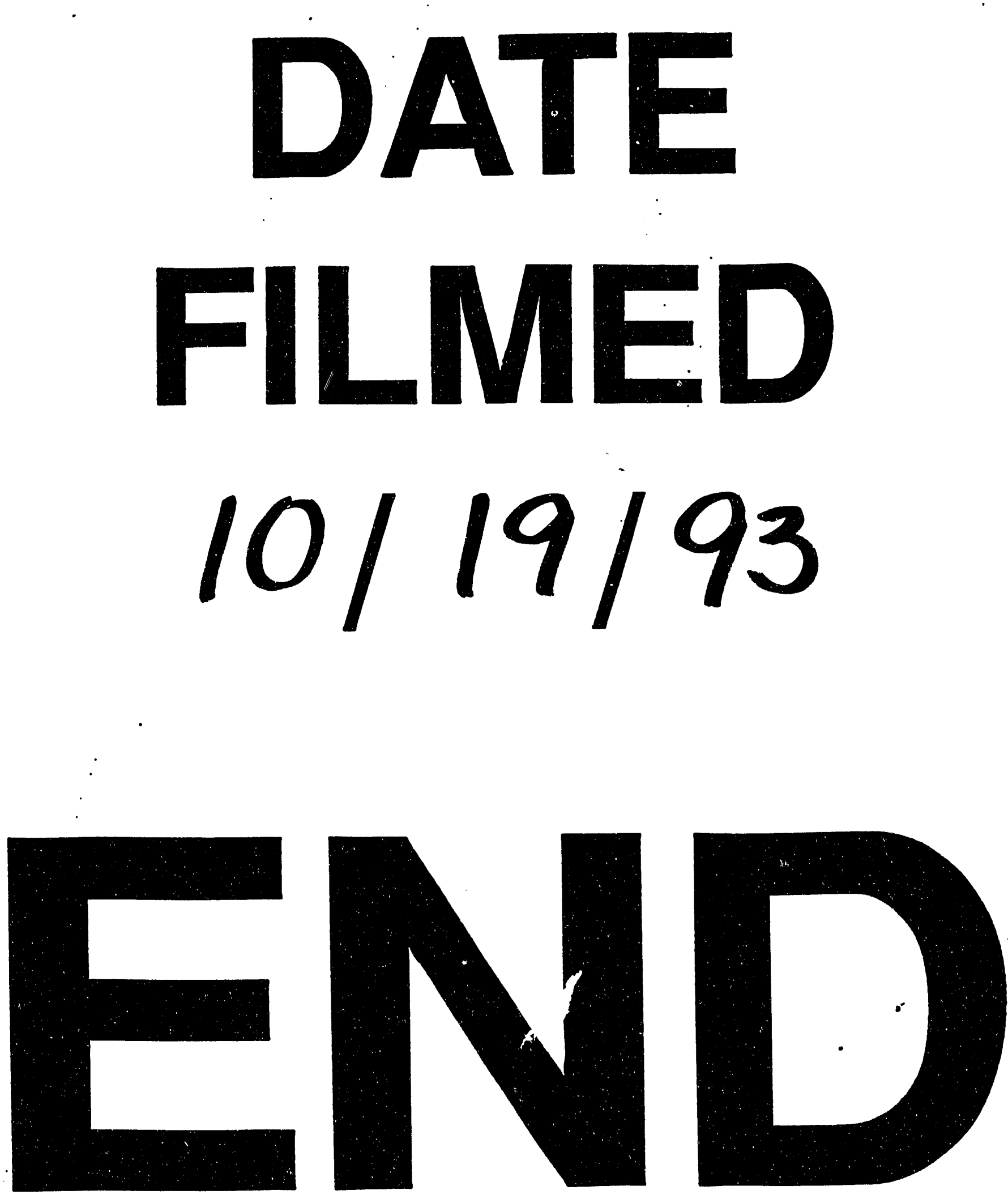
